\title{
Angiotensin receptor blockade attenuates cigarette smoke-induced lung injury and rescues lung architecture in mice
}

\author{
Megan Podowski, ${ }^{1}$ Carla Calvi, ${ }^{1}$ Shana Metzger, ${ }^{1}$ Kaori Misono, ${ }^{1}$ Hataya Poonyagariyagorn,
} Armando Lopez-Mercado, ${ }^{1}$ Therese Ku, ${ }^{1}$ Thomas Lauer, ${ }^{2}$ Sharon McGrath-Morrow, ${ }^{2}$ Alan Berger, ${ }^{3}$ Christopher Cheadle, ${ }^{3}$ Rubin Tuder, ${ }^{4}$ Harry C. Dietz, ${ }^{5}$ Wayne Mitzner, ${ }^{6}$ Robert Wise, ${ }^{1}$ and Enid Neptune ${ }^{1}$

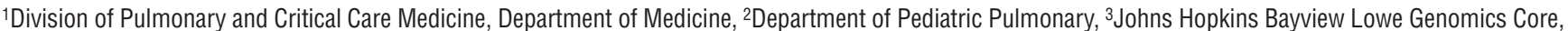
and 4 Division of Cardiopulmonary Pathology, Johns Hopkins University School of Medicine, Baltimore, Maryland, USA. 5 Institute of Genetic Medicine, Howard Hughes Medical Institutes, Johns Hopkins School of Medicine, Baltimore, Maryland, USA. ${ }^{6}$ Department of Environmental Health Sciences, Bloomberg School of Public Health, Johns Hopkins School of Public Health, Baltimore, Maryland, USA.

\begin{abstract}
Chronic obstructive pulmonary disease (COPD) is a prevalent smoking-related disease for which no diseasealtering therapies currently exist. As dysregulated TGF- $\beta$ signaling associates with lung pathology in patients with COPD and in animal models of lung injury induced by chronic exposure to cigarette smoke (CS), we postulated that inhibiting TGF- $\beta$ signaling would protect against CS-induced lung injury. We first confirmed that TGF- $\beta$ signaling was induced in the lungs of mice chronically exposed to CS as well as in COPD patient samples. Importantly, key pathological features of smoking-associated lung disease in patients, e.g., alveolar injury with overt emphysema and airway epithelial hyperplasia with fibrosis, accompanied CS-induced alveolar cell apoptosis caused by enhanced TGF- $\beta$ signaling in CS-exposed mice. Systemic administration of a TGF- $\beta$-specific neutralizing antibody normalized TGF- $\beta$ signaling and alveolar cell death, conferring improved lung architecture and lung mechanics in CS-exposed mice. Use of losartan, an angiotensin receptor type 1 blocker used widely in the clinic and known to antagonize TGF- $\beta$ signaling, also improved oxidative stress, inflammation, metalloprotease activation and elastin remodeling. These data support our hypothesis that inhibition of TGF- $\beta$ signaling through angiotensin receptor blockade can attenuate CS-induced lung injury in an established murine model. More importantly, our findings provide a preclinical platform for the development of other TGF- $\beta$-targeted therapies for patients with COPD.
\end{abstract}

\section{Introduction}

Smoking-related lung diseases, especially chronic obstructive pulmonary disease (COPD) and emphysema, are the third leading cause of death in the United States. Treatment options are limited to either symptom relief and/or the elimination of environmental cofactors such as cigarette smoking. Importantly, despite growing data on the cellular, molecular, and, recently, genetic features of the disorder, no novel treatments that can alter the natural history of the disease are currently available (1). In the studies described here, we extend a therapeutic approach that has demonstrated efficacy in genetically defined murine models of airspace enlargement to a murine model of cigarette smoke-induced (CS-induced) lung injury. Common to these models are the dual findings of perturbation of the cytokine TGF- $\beta$ and airspace enlargement. Therapeutic targeting of TGF- $\beta$ signaling in murine models of Marfan syndrome that display progressive airspace enlargement improves airspace caliber $(2,3)$. Importantly, we reported a reversal in airspace enlargement in adult fibrillin-1-deficient mice that were treated over several months with a neutralizing antibody to TGF- $\beta$ (2). These findings suggested that antagonism of TGF- $\beta$ in lung parenchymal disorders marked by enhanced TGF- $\beta$ signaling might provide a reparative milieu for airspace maintenance.

Authorship note: Megan Podowski, Carla Calvi, Shana Metzger, and Kaori Misono contributed equally to this work.

Conflict of interest: The authors have declared that no conflict of interest exists. Citation for this article: J Clin Invest. 2012;122(1):229-240. doi:10.1172/JCI46215.
We reasoned that if TGF- $\beta$ targeting proves effective for murine models of CS-induced airspace enlargement, we would have proof-of-principle evidence that novel translational approaches to COPD can be garnered from genetically defined animal models with consonant pathologic, physiologic, and/or biologic features.

The pleiotropic cytokine, TGF- $\beta$, has distinct effects on lung maturation, homeostasis, and repair mechanisms (4, 5). Genetic association studies of patients with emphysema and histologic surveys of lungs from patients with COPD of varying severity have both implicated disturbances in TGF- $\beta$ signaling as important components of disease pathogenesis (6). Whereas increased TGF- $\beta$ signaling may explain the increased extracellular matrix observed in the distal airways of patients with severe COPD, reduced signaling with suboptimal matrix deposition might compromise repair in the airspace compartment, leading to histologic emphysema. Experimental data support both mechanisms. We recently showed that fibrillin-1-deficient mice have alveolar septation defects that are secondary to excessive TGF- $\beta$ signaling in the airspace compartment (3). We further showed that antagonism of TGF- $\beta$ signaling with angiotensin receptor blockade in adult fibrillin-1-deficient mice with established airspace enlargement improves the airspace phenotype (2). These data suggest that manipulation of TGF- $\beta$ signaling might either promote airspace regeneration and/or reduce airspace destruction. Despite the fact that TGF- $\beta$ is known to be dysregulated in COPD/emphysema, TGF- $\beta$ manipulation has not been explored in models of CS-induced parenchymal lung disease. 


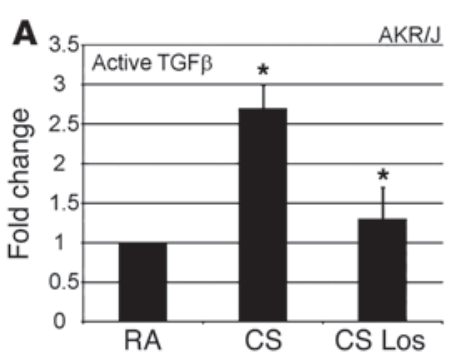

D

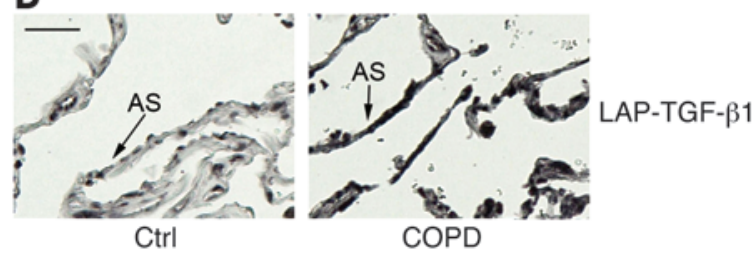

B

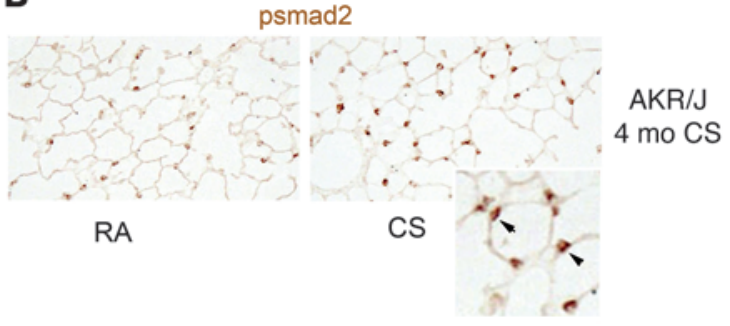

C

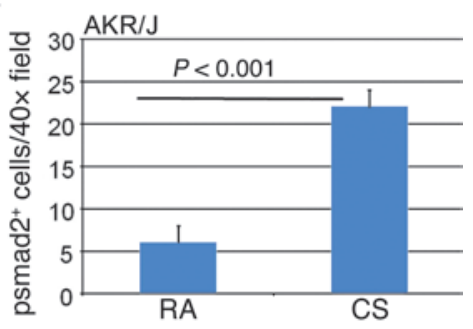

E

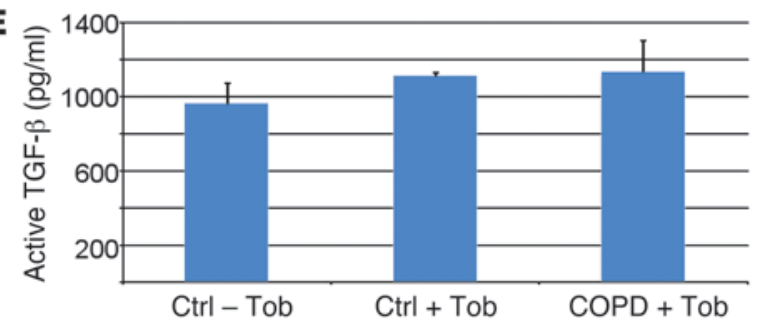

F
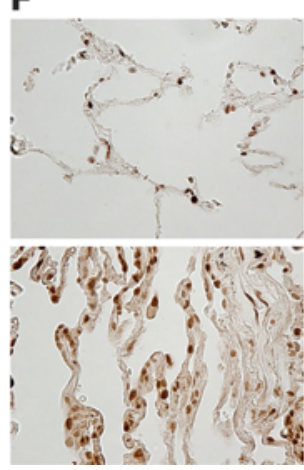

psmad2
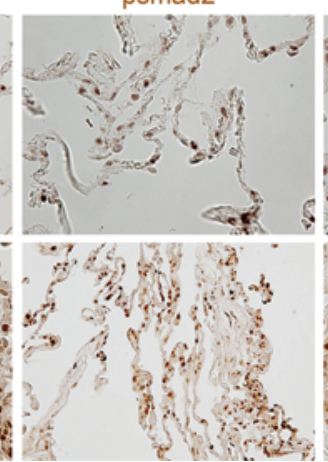

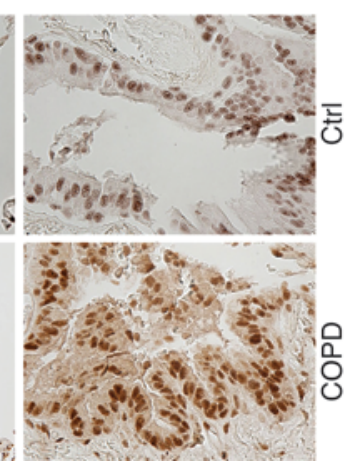

G

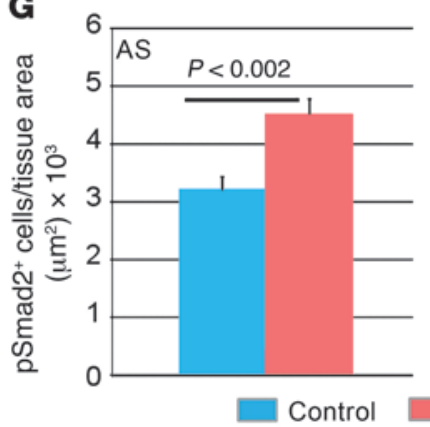

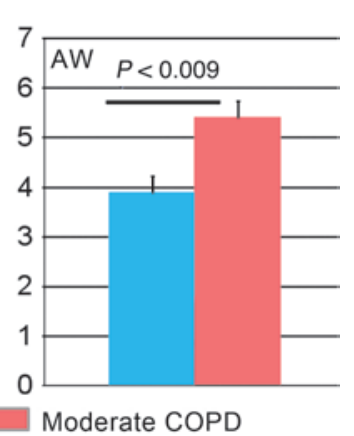

Figure 1

Chronic CS induces TGF- $\beta$ expression in murine lungs and human COPD lungs. (A) TGF- $\beta$ induction profile by ELISA analysis in lung lysates from AKR/J mice exposed to 2 weeks of CS. ${ }^{*} P<0.01$, CS versus RA or CS plus losartan (Los) versus CS. $n=3-5$ mice per treatment group. (B) Representative histologic sections of lungs from mice exposed to RA or chronic CS subjected to immunohistochemical staining for psmad2. The inset shows localized staining in alveolar epithelial cells of CS-exposed mice. Arrowheads denote the site of enhanced staining in airspace (AS) walls of patients with COPD. Original magnification, $\times 20 . n=4-8$ mice per treatment group. (C) Quantitative immunohistochemistry of psmad2 staining in RA- and CS-exposed mice depicted in B. (D) Representative immunohistochemical staining for total TGF- $\beta 1$ in lung sections from a patient with COPD and a control smoker. Original magnification, $\times 40$. Scale bar: $100 \mu \mathrm{m} . n=10$ each of control and COPD tissue sections. LAP-TGF- $\beta 1$, latency-associated peptide TGF- $\beta$ complex. (E) Active TGF- $\beta$ levels in lung lysates from control nonsmokers (Ctrl - Tob) $(n=8)$, control smokers (Ctrl +Tob) $(n=6)$, and smokers with moderate COPD (COPD +Tob) $(n=11)$. (F) Representative immunohistochemical staining for psmad2 in lung sections from a patient with moderate COPD and a control smoker (airspace [2 right panels], airway [left panel]). (G) Quantitative immunohistochemical staining of psmad2 in airspace compartment and airway compartment in lung sections from patients with moderate COPD and smoking controls normalized to tissue area. $n=6-11$ in each group. AW, airway.

The role of the renin-angiotensin-aldosterone (RAA) cascade in the lung is not well described. Apart from known effects on the microvasculature, reflecting the potent vasoconstrictive effects of angiotensin II, enhanced RAA signaling also induces fibrosis in several tissue beds, including the kidney and the myocardium $(7,8)$. These latter effects reflect the ability of angiotensin to promote TGF- $\beta$ expression and signaling. In established rodent models of lung injury and fibrosis, angiotensin seems to initiate a series of critical TGF- $\beta$-dependent perturbations in the airspace (namely, epithelial cell apoptosis and epithelial mesenchymal transformation) that cause acute lung injury and frequently culminate in the fibrotic program. Importantly, angiotensin receptor blockade attenuates tissue fibrosis in such model systems $(9,10)$. Although structural alveolar apoptosis and airway fibrosis are common features of COPD pathogenesis, angiotensin receptor blockade has not as yet been explored in models of COPD/emphysema.

Here we examine the therapeutic utility of TGF- $\beta$ modulation using two pharmacologic strategies in a murine model of CS-induced emphysema. We show increased TGF- $\beta$ signaling in the lungs of mice exposed to CS and the lung parenchyma of patients with moderate COPD. Systemic TGF- $\beta$ antagonism using either a pan-specific-neutralizing antibody or losartan, an angiotensin receptor blocker, improves airway and airspace architecture and lung function in chronic CS-exposed mice, commensurate with normalized injury measures. These studies provide compelling preclinical data supporting the utility of TGF- $\beta$ targeting for CS-induced lung injury. 


\section{Results}

Increased TGF- $\beta$ activity in lungs of mice and lung epithelial cells exposed to $C S$ and in lungs of patients with COPD. We first evaluated whether CS exposure resulted in elevated levels of active TGF- $\beta$ in the lungs of 2 strains of mice known to be sensitive to CS and whether treatment with the angiotensin receptor blocker losartan normalized this induction. Two weeks of CS exposure significantly induced active TGF- $\beta$ as shown by ELISA analysis in both AKR/J mice (2.5 fold) and C57BL/6 mice (1.4 fold) (Figure 1A and Supplemental Figure 1A; supplemental material available online with this article; doi:10.1172/JCI46215DS1). Concurrent losartan treatment normalized TGF- $\beta$ in both strains. To extend these findings to a chronic CS-induced emphysema model, we evaluated phosphorylated Smad2 (psmad2) staining, an index of active TGF- $\beta$ signaling, in lung sections from mice that develop emphysema after 4 months of CS exposure, AKR/J mice, and mice that develop emphysema after 6 months of CS exposure, C57BL/6 mice. Psmad2 staining was increased in the lungs of both strains of CS-exposed mice (Figure 1, B and C, and Supplemental Figure 1, B and C), primarily in alveolar epithelial cells (See inset, Figure 1B). Modest elevations of connective tissue growth factor (CTGF), a downstream marker of TGF- $\beta$ signaling, and TGF- $\beta 1$ were observed in the lung lysates from AKR/J mice exposed to 4 months of CS (Supplemental Figure 2). Treatment of murine lung epithelial cells, MLE12 cells, with CS extract (CSE) also induced enhanced TGF- $\beta$ activation, evident in psmad 2 expression by immunoblotting (Supplemental Figure 3). Finally, to extend this observation to clinical COPD, we examined lung samples from at-risk controls (smokers with normal lung function) and patients with moderate COPD. ELISA analysis of active TGF- $\beta 1$ in lung lysates showed a modest smoking-induced increase in the whole lung levels that was unaffected by COPD status (Figure 1E). However, we consistently observed increased TGF- $\beta 1$ and psmad 2 in the airspaces of patients with moderate COPD, when compared with those of smoking controls (Figure 1, $\mathrm{D}, \mathrm{F}$, and $\mathrm{G}$ ). We chose patients with moderate COPD rather than severe COPD to avoid the end-stage effects often seen with severe COPD that is punctuated by extensive airspace destruction and overall reduced protein expression. The TGF- $\beta 1$ in the lungs of these patients with COPD was localized to the alveolar septal walls (similar to that in the murine models) and to inflammatory cells. These data implicate elevated TGF- $\beta$ signaling as a component of CS-induced lung injury.

TGF- $\beta$ antagonism improves airspace enlargement in chronic CS-exposed mice. The losartan effect on TGF- $\beta$ signaling after short-term CS exposure suggested that angiotensin receptor blockade might have salutary effects on long-term sequelae of CS exposure. We elected to use the AKR/J strain in subsequent experiments for 2 reasons: (a) to incorporate shorter-term chronic exposures that still generate a measurable airspace lesion and (b) to use an inbred strain that has a CS-induced inflammatory profile more consistent with that of a typical patient with COPD than that of the conventional C57BL/ 6 model (11). Unfortunately, most investigators still use the $\mathrm{C} 57 \mathrm{BL} / 6$ model that has the potential shortcomings of showing mild lesions with no evidence of airway pathology when exposed to CS. To establish the earliest time point at which we could observe an increase in airspace dimension, the signature feature of emphysema, we exposed AKR/J mice to CS for 1, 2, and 4 months and performed morphometric analysis. Although no increase in airspace dimension was observed after of 1 month of exposure, significant emphysema developed after 2 months (Figure 2A). (We also find age-related increases in airspace dimension in room air-exposed [RA-exposed] mice, a finding we recently dissected in another inbred strain but notably occurs earlier in the AKR/J mice [ref. 12].) We treated mice with losartan at 2 doses, $0.6 \mathrm{~g} / \mathrm{l}$ losartan (low dose) or $1.2 \mathrm{~g} / 1$ losartan (high dose) in drinking water, concurrent with the CS exposure and found a marked reduction in the airspace dimension after 2 months (Figure 2, B and C). RA-exposed mice treated with the 2 doses of losartan showed no change in airspace caliber or histology compared with those of untreated controls (Figure 2B and Supplemental Figure 4). Assessment of airway attachments, a measure of airspace destruction, showed a significant reduction with CS but recovery with losartan treatment (Figure 2D). By contrast, CS-induced weight loss was not improved with either losartan or TGF- $\beta$-neutralizing antibody treatment (Supplemental Figure 5). Losartan treatment of RA-exposed mice did not alter body weight.

To test the hypothesis that these effects were mediated by inhibition of TGF- $\beta$, we treated CS-exposed mice with a neutralizing antibody to TGF- $\beta(2,3)$. Similar to losartan, TGF- $\beta$ antagonism with neutralizing antibody given concurrently with CS improved airspace dimension compared with that of CS-exposed mice treated with isotype-matched control antibody (Figure 2B). RA-exposed mice treated with the neutralizing antibody showed no change in airspace caliber or histology compared with those of untreated controls (data not shown). Phosphorylated smad2 was increased in the alveolar and airway epithelium in CS-exposed mice and normalized with losartan treatment (Figure 2, E and F). Thus, two different strategies targeting TGF- $\beta$ signaling result in improved airspace dimension.

Losartan treatment results in improved lung mechanics and airway histology in chronic CS-exposed mice. The critical disturbance that drives clinical disease in COPD is the attendant alteration in lung function that follows from altered lung histology. Compared with those of RA-exposed mice, CS-exposed mice had increased lung size and reduced lung elastance, typical physiologic disturbances in emphysema (Figure 3). Losartan normalized lung size and lung elastance, suggesting that the protective effects apparent by lung histology translated into improved lung function. Of note, losartan treatment of RA-exposed mice did not significantly alter lung mechanics, although there was a trend toward increased elastance.

Mice exposed to CS developed mucosal thickening that approximated the epithelial hyperplasia observed in patients with COPD/emphysema (Figure 4A and ref. 13). We measured epithelial thickness in airways of similar size in mice exposed to RA, CS, CS plus losartan, and CS plus TGF- $\beta$-neutralizing antibody. CS produced a greater than 2 -fold increase in airway mucosal thickness (Figure 4A). Airway epithelial thickening normalized with losartan treatment and TGF- $\beta$-neutralizing antibody treatment. No increase in PAS staining (goblet cells) was observed in the CS-exposed airways (data not shown). We performed Ki67 staining of the airway compartment to determine whether the airway thickening represented a proliferative process possibly triggered by CS exposure. We observed an increase in airway epithelial proliferation with CS exposure, with a trend toward reduction with losartan treatment (Figure 4B). Since TGF- $\beta$ can induce small airway remodeling, we examined collagen deposition in CS-exposed lungs. While only a minimal increase in collagen deposition was seen in mice exposed to 2 months of CS, a marked increase in peribronchiolar collagen deposition was observed in mice exposed to 3 months of CS (Figure 4C). Losar- 

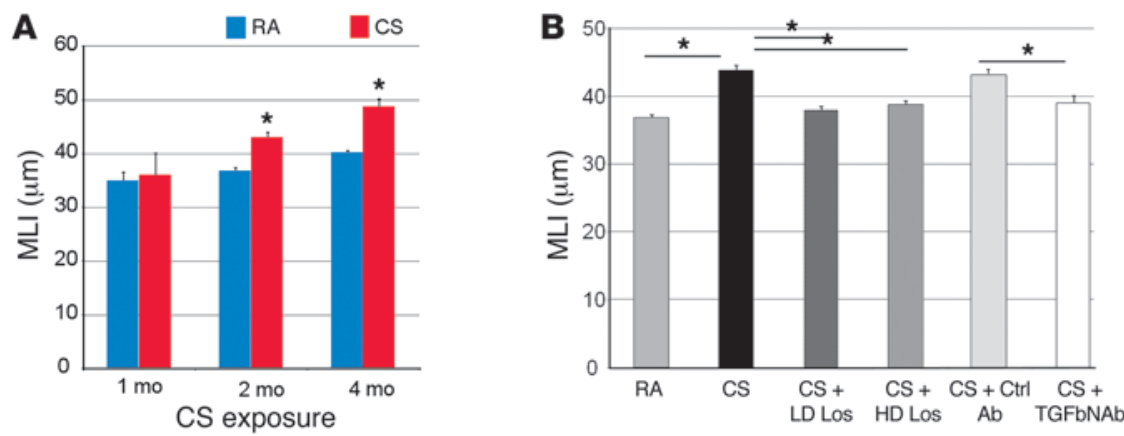

C
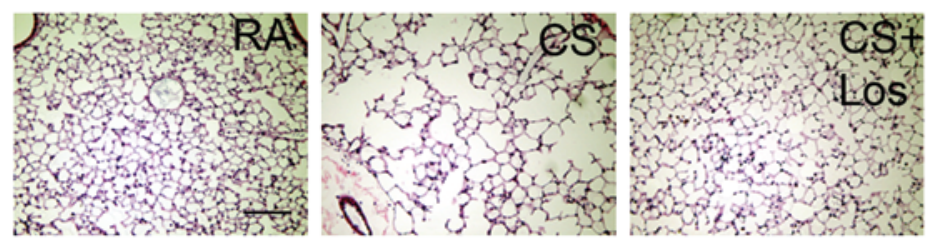

D

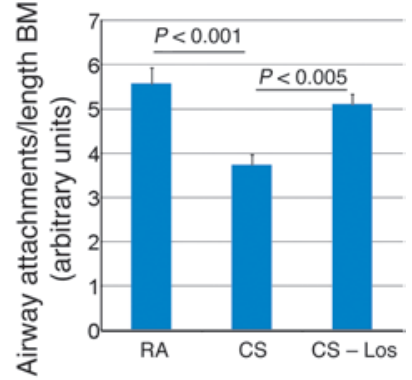

E

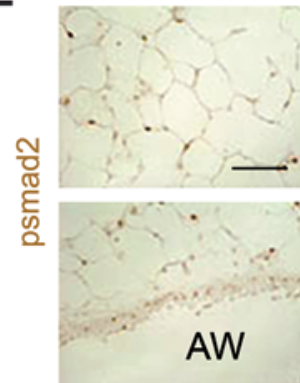

RA

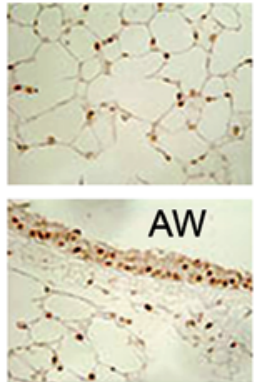

CS

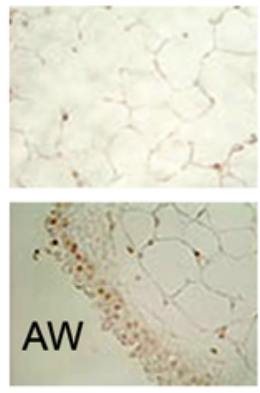

CS + Los
F

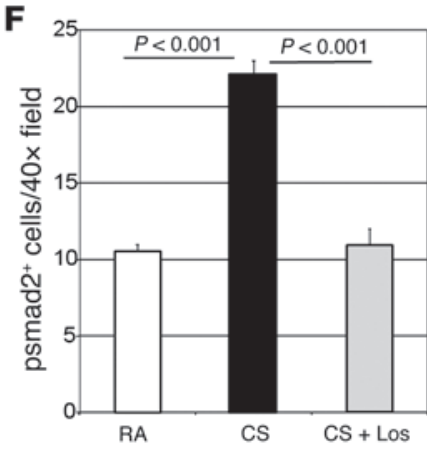

Figure 2

Losartan and TGF- $\beta$-neutralizing antibody inhibit chronic CS-induced TGF- $\beta$ signaling in the lung and attenuate destructive airspace enlargement. (A) Morphometric analysis of airspace dimension assessed by mean linear intercept (MLI) in mice subjected to 1 month, 2 months, and 4 months of CS exposure. $n=10-25$ mice per treatment group. ${ }^{*} P<0.01$. (B) Morphometric analysis of airspace dimension in mice subjected to 2 months of RA with drinking water or 2 months of CS exposure with drinking water, concurrent low-dose losartan (LD, $0.6 \mathrm{~g} / \mathrm{l})$, high-dose losartan (HD, 1.2 $\mathrm{g} / \mathrm{l})$, control antibody, or TGF- $\beta$-neutralizing antibody (TGFNAb) $(10 \mathrm{mg} / \mathrm{kg} / \mathrm{wk})$. ${ }^{*} P<0.01$, RA versus CS or CS versus CS plus other treatments. $n=6-8$ mice per treatment group. (C) Representative H\&E photomicrographs of lungs from mice subjected to 2 months of CS exposure with or without losartan treatment compared with RA controls. Original magnification, $\times 20$. Scale bar: $200 \mu \mathrm{m}$. (D) Airway alveolar attachment count in mice subjected to the designated treatments. $n=6-8$ mice per treatment group. BM, basement membrane. (E) Representative photomicrographs of lungs subjected to CS compared with RA controls or CS plus losartan stained for psmad2 (brown), a marker of TGF- $\beta$ signaling (airspace compartment [top panel], airway compartment [bottom panel]). Original magnification, $\times 40$. Scale bar: $50 \mu \mathrm{m}$. (F) Quantitative immunohistochemistry of psmad2 staining of lungs from aforementioned treatment groups. $n=6-8$ mice per treatment or condition. CS + Los, CS plus losartan.

tan normalized collagen deposition in such mice. The density and abundance of $\alpha$ SMA-producing smooth muscle cells surrounding the small airways was not changed with CS or losartan treatment (data not shown). We thus propose that this airway lesion is a direct toxic effect of CS and involves TGF- $\beta$ dysregulation. In summary, airspace enlargement, airway epithelial thickening, peribronchiolar fibrosis, and altered lung mechanics were all ameliorated by losartan treatment and TGF- $\beta$ antagonism.

TGF- $\beta$ antagonism improves CS-induced oxidative stress, inflammation, and cell death. Oxidative stress and inflammation mediate CS-induced lung injury in patients with COPD and murine models of acquired emphysema $(14,15)$. In $\mathrm{AKR} / \mathrm{J}$ mice exposed to 2 weeks or 2 months of CS, nitrotyrosine and 8-deoxyguanine immunostaining were increased (Figure 5, A and B, and data not shown), as were alveolar macrophage and lymphocyte numbers (Figure 5, C and D). Of note, we saw no increase in neutrophils in the CS-exposed lungs (data not shown). Losartan treatment normalized oxidative stress and reduced inflammatory cell infiltration into the CS-exposed lungs (Figure 5, A-D). TGF- $\beta$ is known to not only inhibit cellular proliferation, a property observed in various epithelial model systems, but also induce cell death, notably in the alveolar lung cells, as seen in fibrillin-1-deficient mice (3). We did see reduced airspace epithelial cell proliferation with CS exposure that did not normalize with 

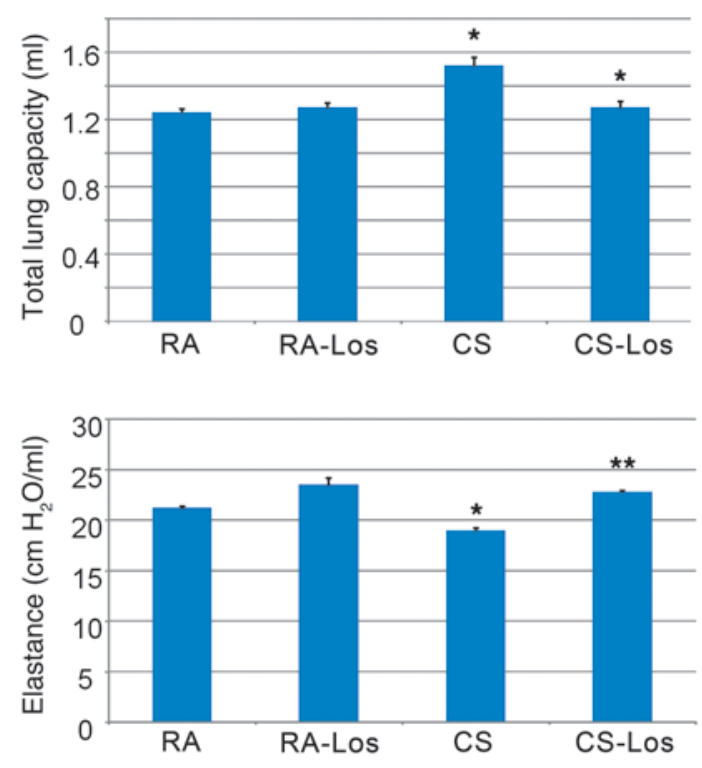

\section{Figure 3}

Effect of losartan treatment on lung mechanics of CS-exposed mice. Total lung capacity of lungs subjected to designated treatments (top). Static lung elastance of mice subjected to designated treatments (bottom). ${ }^{\star} P<0.05$ for CS compared with RA; ${ }^{* *} P<0.05$ for CS and losartan compared with CS. $n=6-8$ mice per treatment or condition. Data are represented as mean \pm SEM.

losartan treatment (data not shown). By contrast, the enhanced TUNEL and active caspase- 3 labeling in the airspace, indicating alveolar epithelial apoptosis, with smoke exposure was attenuated by losartan treatment (Figure 5, E and F).

Effects of losartan on metalloprotease activation and elastin integrity in the CS airspace. To further assess mechanisms by which elevated TGF- $\beta$ might directly induce airspace enlargement, we evaluated metalloprotease activation and matrix turnover. Zymography showed increased MMP9, but not MMP2, activation with CS exposure compared with that after exposure to RA. MMP9 activation was normalized by losartan treatment (Figure 6, A and B). Interestingly, we also observed a modest induction of MMP12 expression in the lungs of CS-exposed mice that was normalized by losartan treatment (Figure 6C). We examined elastin fragmentation in the airspaces of CS-exposed mice and found discontinuous elastin staining with areas of clumping, which were improved by losartan treatment (Figure 6D). These data suggest that anti-TGF- $\beta$ therapy may confer a protective milieu for the extracellular matrix in the CS-exposed lung.

Taken together, both metalloprotease activation and apoptotic cell death are the likely underlying mechanisms for the CS-induced airspace enlargement and are both ameliorated by anti-TGF- $\beta$ pharmacologic maneuvers.

CS alters angiotensin receptor localization and expression in the murine lung. Because losartan is a specific angiotensin receptor type 1 (AT1) antagonist, we considered whether CS exposure dysregulated AT1 expression in a manner that enhanced the therapeutic utility of angiotensin receptor blockade. Using real-time PCR, we found no differences in AT1 receptor expression conferred by CS exposure (Figure 7A). Angiotensin receptors are known to be expressed on lung epithelial cells, with AT1 localized primarily to the lung parenchyma $(16,17)$.
Since receptor localization is a critical factor in defining the mechanism of losartan's effects, we performed immunohistochemistry for the AT1 receptor on murine lungs subjected to RA, CS, and CS plus losartan and found that it localized to the alveolar wall and airway subepithelial mesenchymal layer (Figure 7B). CS increased AT1 staining in the airspace walls; this was normalized with losartan treatment (Figure 7, B and inset of B). We propose that the therapeutic losartan effects that we see in CS-exposed mice may partially reflect increased expression of angiotensin receptor 1 in the lung parenchyma that is induced by CS but normalized by losartan.

Transcriptomic signature of therapeutic effect with losartan in CS lung. The current dearth of rational therapies for COPD/emphysema prompted us to attempt identification of nonintuitive pathways that could be exploited for therapeutic targeting. To do this, we performed an expression profile analysis of lungs from mice exposed to RA, 2 months CS, or 2 months CS plus losartan. A panel of genes dysregulated with CS and either further dysregulated or normalized when treated with losartan was generated (Supplemental Figure 6A). We surmised that genes induced or repressed with CS and then partially or fully normalized with losartan might represent pathways that contribute to the CS-induced injury phenotype. By contrast, we postulated that genes primarily dysregulated with CS and then further dysregulated with losartan likely reflect reparative pathways triggered with CS exposure and further reinforced by angiotensin receptor blockade. We found that stress response and MAPK pathway genes were downregulated with CS but induced with losartan treatment. Conversely, oxidoreductase, $\mathrm{B}$ cell receptor signaling, chemokine signaling, and cytokine receptor interaction pathways were induced with CS but repressed with losartan treatment. These findings suggest that whereas survival pathways may be blunted with CS exposure but restored with losartan treatment, oxidative stress signaling and immune cell activation pathways are induced with CS and ameliorated with losartan treatment. Both profiles are consistent with our demonstration that losartan reduces CS-induced oxidative stress and inflammation (Figure 4).

To further examine cell survival mechanisms that might be altered by CS but restored by losartan, we explored TGF- $\beta$-induced pathways that converge onto canonical survival kinase cascades (p21, p38, JNK, and PI3K/Akt) (18-21). We focused on p21 (proapoptotic/antiapoptotic), p38 (proapoptotic), JNK (proapoptotic), and akt (antiapoptotic), since these can be modulated by TGF- $\beta$. Since signaling measurements using total lung lysates are reflective of the composite of the multiple compartments present in the lung parenchyma rather than the site of relevant activity, we elected to use both immunoblotting and in situ surveys to assess prosurvival signaling with CS exposure and losartan treatment. We saw no evidence of p21 induction or activation, respectively, in CS-exposed lungs (data not shown). We observed attenuated Akt, JNK, and p38 activation by immunoblotting in CS-exposed lungs (Supplemental Figure 6B). However, only Akt activation was normalized by losartan treatment (Supplemental Figure 6C). These data suggest that a candidate mechanism by which losartan improves airspace dimension is by enhancing Akt-mediated prosurvival signaling and reducing alveolar apoptosis. We examined the distribution of akt staining in the lung and found localization in the airspace epithelial cells (Supplemental Figure 6, D and E). The reduction in staining in the airspace compartment with CS suggested that the immunoblotting pattern reflected events at the site of known CS-induced lung pathology. 

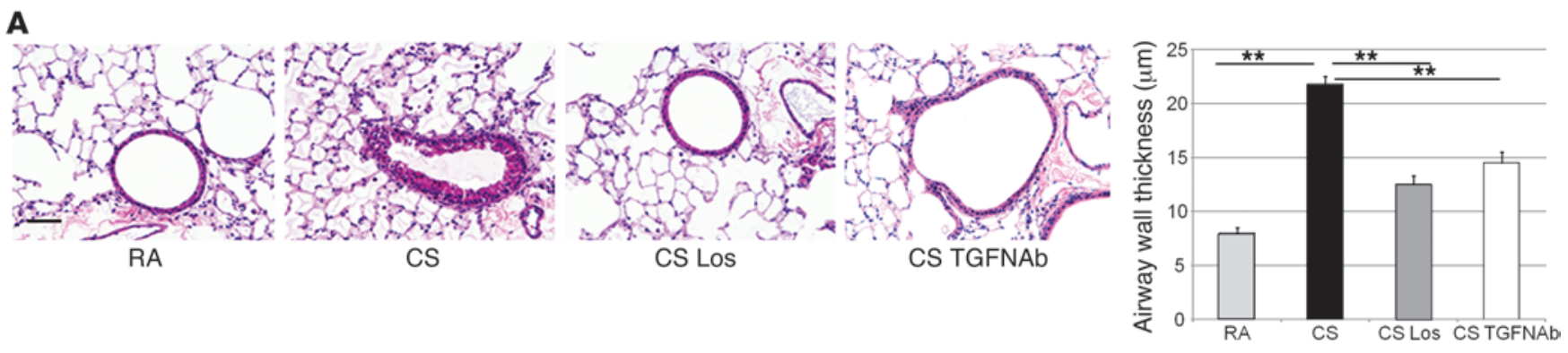

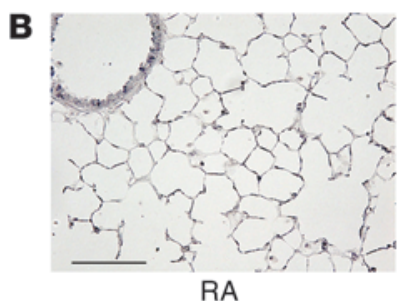

RA

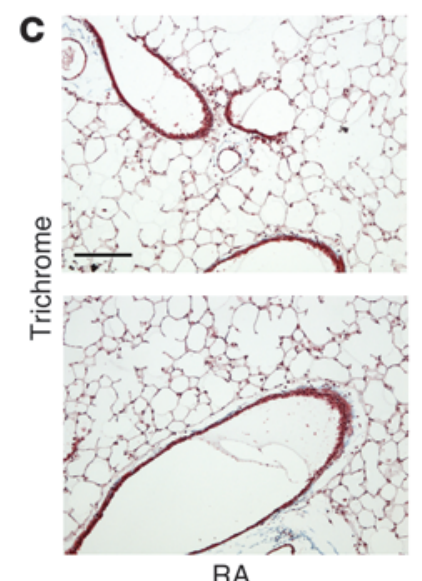

RA

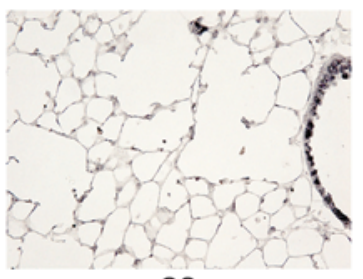

CS

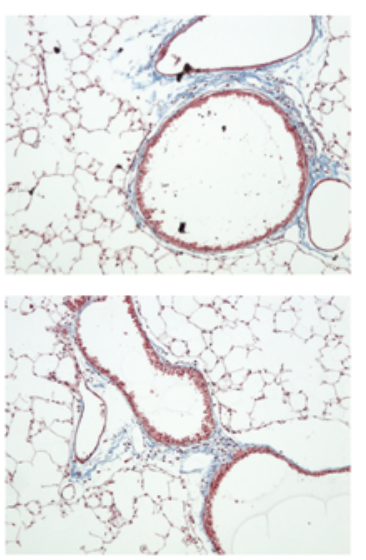

CS

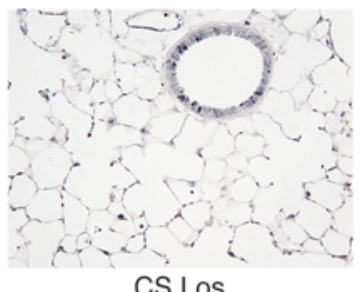

CS Los
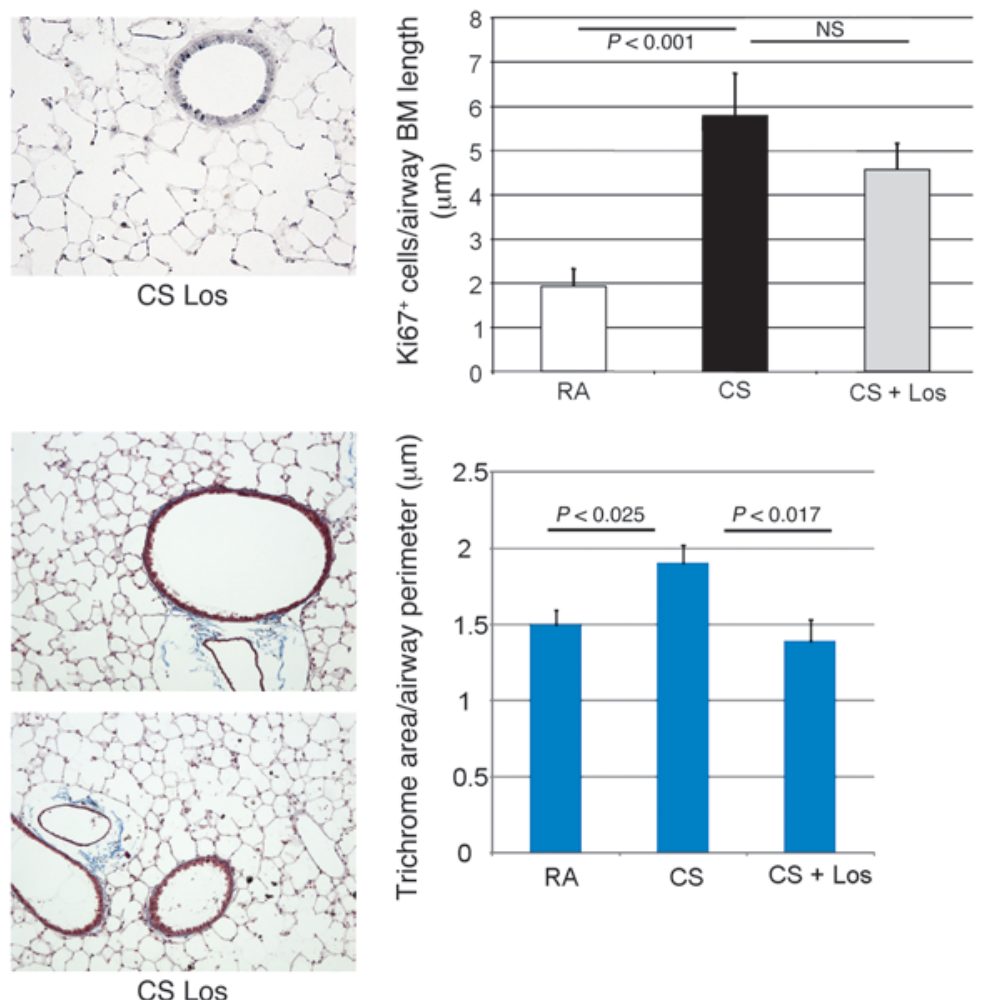

\section{Figure 4}

Airway wall thickening and epithelial hyperplasia in chronic CS-exposed mice. (A) Representative H\&E images of small airways from mice treated with 2 months of RA, CS, CS plus losartan, or CS plus TGF- $\beta$-neutralizing antibody (TGFNAb). Original magnification, $\times 20$. Scale bar: $50 \mu \mathrm{m}$. Measurement of airway wall thickness of small airways of similar caliber in mice subjected to designated treatments. Data are expressed as mean \pm SEM. ${ }^{* *} P<0.01 . n=6-8$ mice per treatment. (B) Representative lung sections of airways from mice in designated treatment groups stained for proliferation marker Ki67. $n=4-6$ mice per group. Original magnification, $\times 20$. Scale bar: $100 \mathrm{~mm}$. Quantitative immunohistochemistry of Ki67 staining of airway epithelial cells. (C) Representative images of trichrome staining of airways from mice in designated treatment groups. Original magnification, $\times 20$. Scale bar: $100 \mu \mathrm{m}$. Quantitation of trichrome staining in designated groups normalized to airway perimeter. $n=7-9$ mice per group.

\section{Discussion}

The role of TGF- $\beta$ dysregulation in CS-induced COPD/emphysema is a controversial issue, given abundant but conflicting data showing evidence of both enhanced and reduced activity in the COPD lung. We show here evidence of increased TGF- $\beta$ activity in the airspaces of chronic CS-exposed mice and patients with mild COPD. We further establish that pharmacologic inhibition of TGF- $\beta$ signaling protects the murine lung from altered lung histology, impaired lung function, and a panel of injury measures that accompany CS-induced lung disease. Whereas emphysema was originally thought to solely require elastin destruction, the current pathogenetic schema incorporates additional mechanisms, such as cell death and oxidative stress injury $(22,23)$.
Importantly, the pleiotropic effects of TGF- $\beta$ signaling impact on all of these contributing mechanisms. This study provides compelling preclinical evidence for the utility of TGF- $\beta$ targeting for common and complex CS-promoted lung pathologies, such as COPD/emphysema and respiratory bronchiolitis.

TGF- $\beta$ signaling incorporates a large family of ligands, cellsurface receptors, and coreceptors that engage a complex but canonical cascade of intracellular mediators to modulate tissue morphogenesis and repair. TGF- $\beta$ has multiple functions in the airspace, a compartment composed of multiple cell types of endodermal, mesenchymal, vascular, and hematopoietic lineage. The response to TGF- $\beta$ in each of these cell types is distinct and context dependent (reviewed in ref. 24). What is clear 

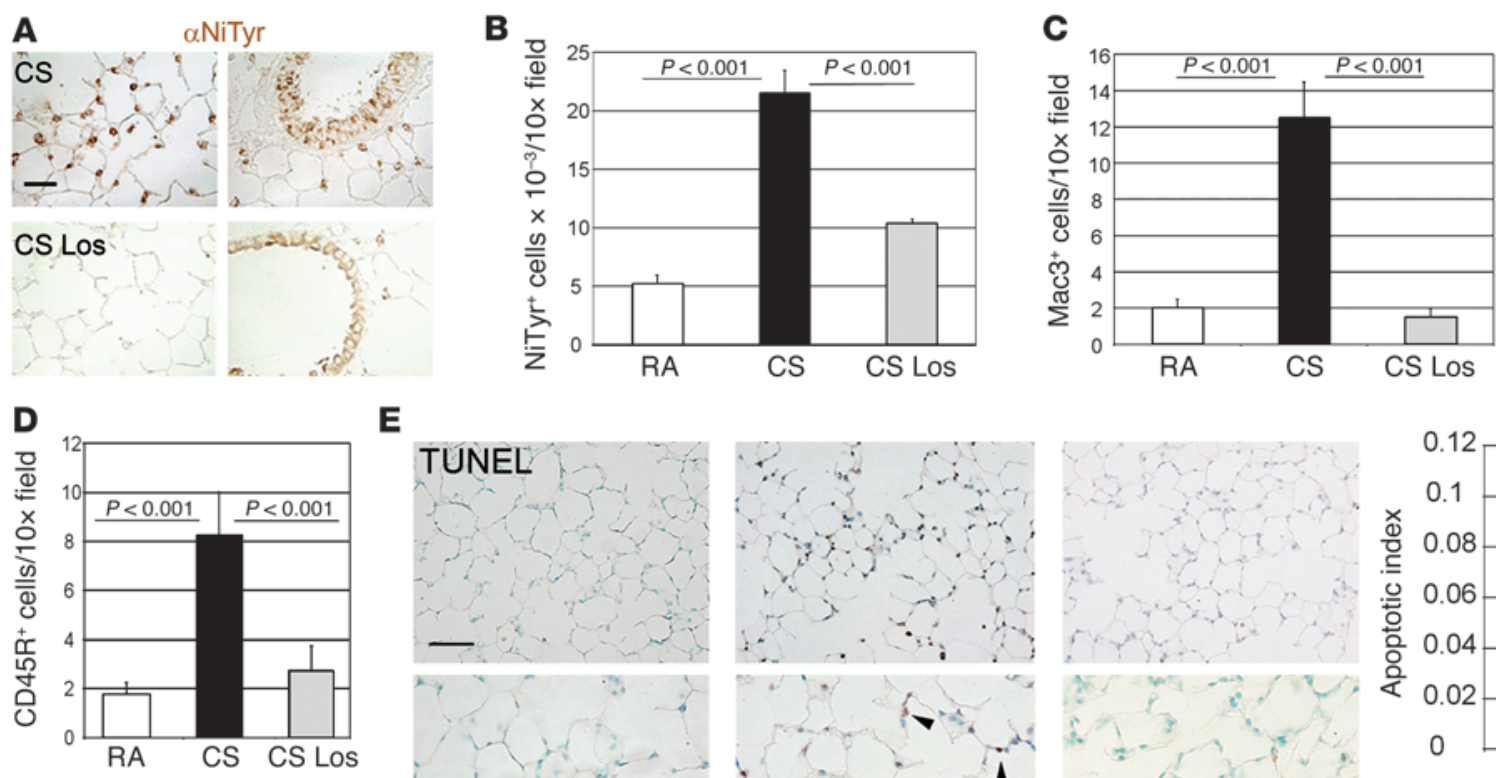

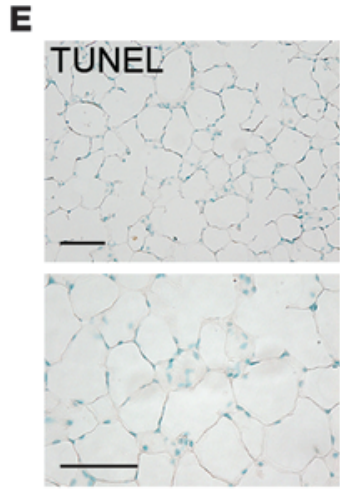

RA

$\mathbf{F}$

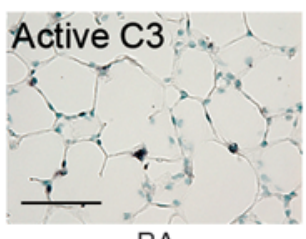

RA

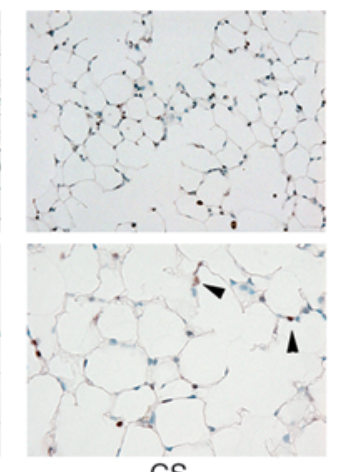

CS

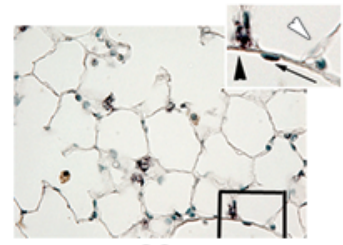

CS
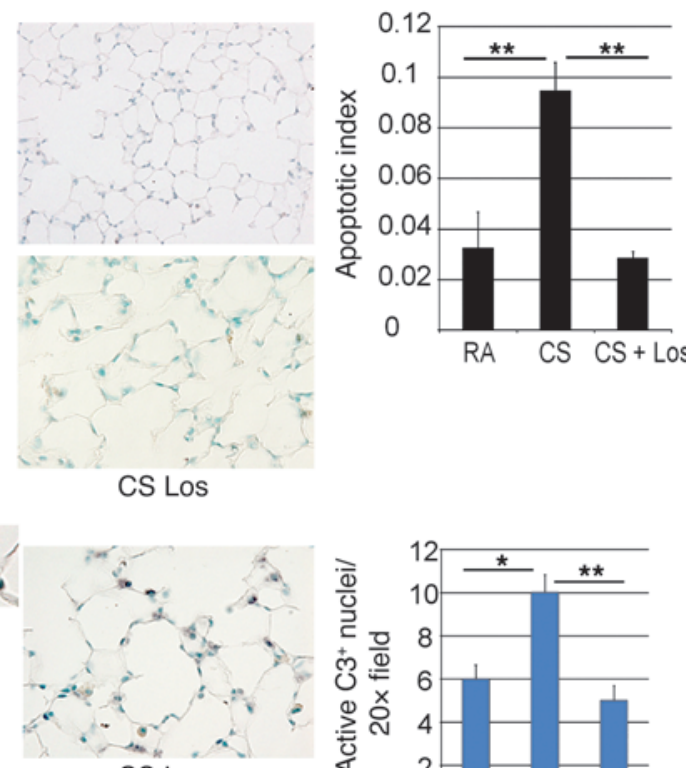

CS Los

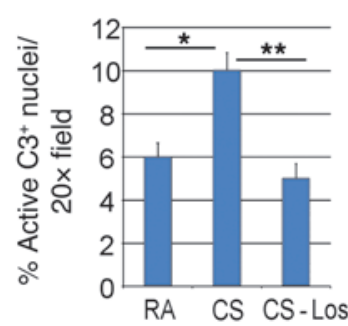

Figure 5

Effect of losartan on CS-induced injury measures. (A) Nitrotyrosine (NiTyr) staining (brown) of lung parenchyma (right) and airways (left) of lungs exposed to CS or CS plus losartan. Original magnification, $\times 40$. Scale bar: $50 \mu \mathrm{m} . n=4-6$ mice per group. (B) Quantitative immunohistochemistry of nitrotyrosine-stained lungs. Staining was normalized to tissue area. $n=4-6$ mice per group. (C) Quantitative immunohistochemistry of macrophage abundance in lungs using MAC3 staining. Staining was normalized to tissue area. $n=4-6$ mice per group. (D) Quantitative immunohistochemistry of lymphocyte abundance in lungs using CD45R staining. Staining was normalized to tissue area. $n=4-6$ mice per group. (E) Representative photomicrographs of TUNEL-stained lungs. Arrowheads denote staining in airspace epithelial cells in CS-exposed lungs. Original magnification, $\times 20$ (top row); $\times 40$ (bottom row). Scale bar: $50 \mu \mathrm{m} . n=4-6$ mice per condition or per treatment. Quantitative immunohistochemistry of TUNEL staining reflecting the apoptotic index. Data are represented as mean \pm SEM. (F) Representative photomicrographs of active caspase-3-stained (C3-stained) lungs. The black arrowhead denotes positive staining in type II alveolar epithelial type II cell. The white arrowhead denotes negative staining in nearby type II epithelial cell. The black arrow shows lack of staining in type I alveolar epithelial cell. Original magnification, $\times 40$. Scale bar: $50 \mu \mathrm{m} . n=4-6$ mice per condition or per treatment. Quantitative immunohistochemistry of active caspase-3 staining normalized to tissue area. Data are represented as mean \pm SEM. ${ }^{*} P<0.05,{ }^{* *} P<0.01$.

is that the homeostatic level of TGF- $\beta$ is well maintained, and interventions directed toward correcting excess in either direction are reasonable strategies. Although TGF- $\beta$ can induce fibroblast cell differentiation into highly synthetic myofibroblasts and arguably transdifferentiation of epithelial cells into fibroblasts, the pathway can have prominent antiproliferative and proapoptotic effects in the epithelial compartment $(14,25)$. Our observation of a prominent proapoptotic effect in the airspace epithelial compartment of CS-exposed lungs accompanying peribronchial fibrosis is consistent with a TGF- $\beta$-mediated profile. However, TGF- $\beta$ effects in most tissues are dictated by both cellular context and signaling intensity, with a physiologic window defined by the optimal level of ambient ligand abundance and cellular capacity for response. The selective epithelial and peribronchiolar response to TGF- $\beta$ signaling in our model suggests that chronic CS induces an elevation of TGF- $\beta$ sufficient to compromise epithelial cell survival and promote submucosal fibrosis in the distal airway but not to induce an interstitial fibrotic program. Of note, most TGF- $\beta$ transgenic overexpression maneuvers in the lung result in exuberant pathway activation and therefore culminate in parenchymal fibrosis $(26,27)$. However, selective TGF- $\beta$-overexpressing mice as well as nonfibrotic rodent injury models associated with elevated TGF- $\beta$ levels consistently show early airspace enlargement with 

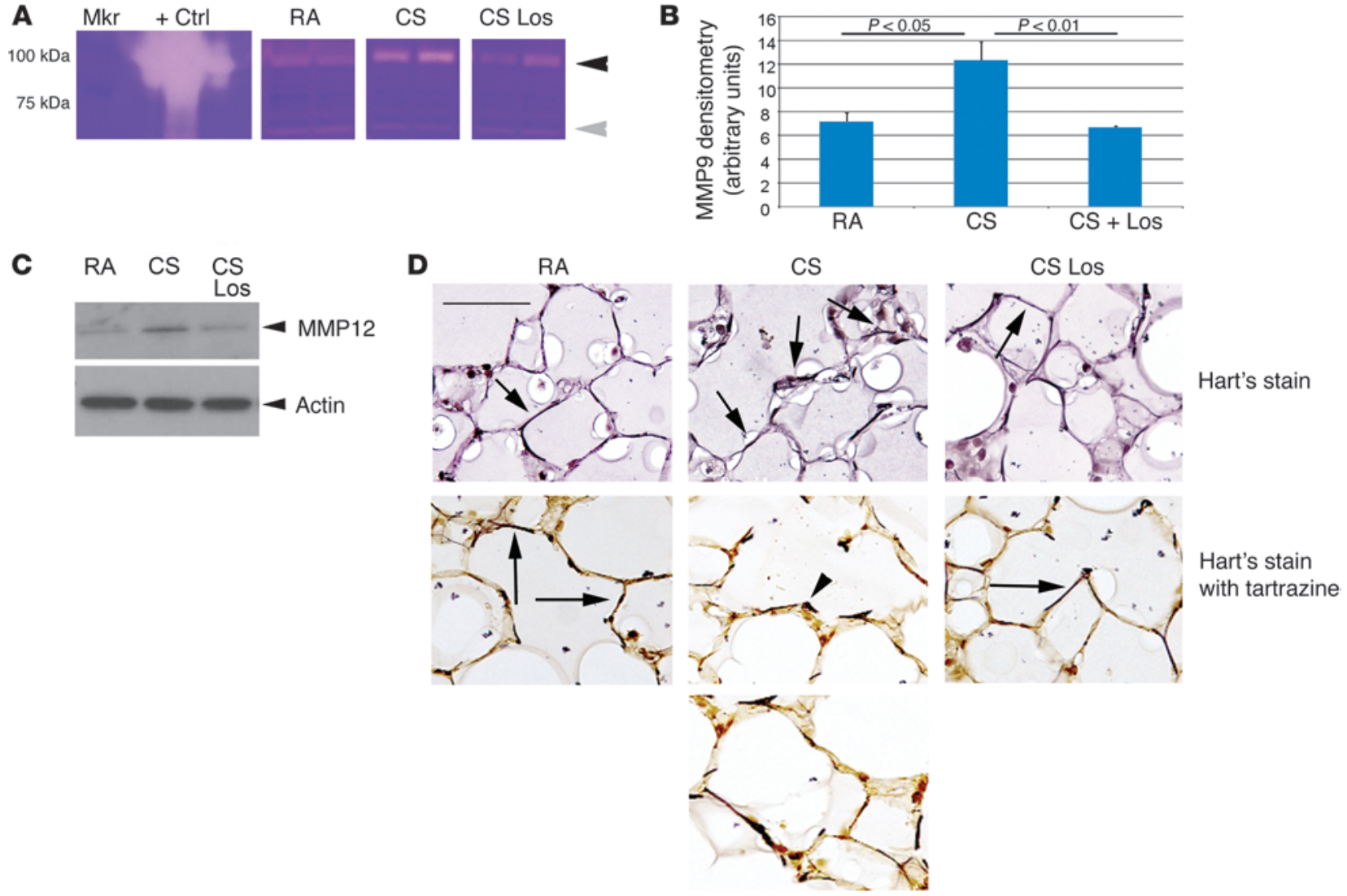

\section{Figure 6}

Effects of losartan on matrix metalloprotease activity and expression. (A) Zymography of lung extracts from representative mice with designated exposures and treatments. The top band (black arrowhead) denotes MMP9, and the lower band (gray arrowhead) denotes MMP2. The positive (+) control data represents recombinant mouse MMP9. The lanes were run on the same gel but are noncontiguous. $n=4-8$ mice per treatment. (B) Densitometry of MMP9 zymography bands. $n=4-8$ mice per treatment. (C) Western blot analysis of MMP12 expression in lung lysates from mice exposed to RA, CS, or CS plus losartan. MMP12 and $\beta$-actin bands are shown. $n=4-6$ mice per condition. (D) Elastin localization by Hart's stain with and without tartrazine counterstaining. Arrows in the top and middle rows show linear deposition of elastin in alveolar walls of RA-exposed mice, and arrowheads show dense, discontinuous deposition in walls in CS-exposed mice. The latter is improved with losartan treatment (arrow). Note that pale staining in airspaces reflects residual agarose in lungs. Scale bar: $50 \mu \mathrm{m}$. $n=4-6$ mice per condition.

variable components of mild fibrosis (28-30). Thus, the compartmentalized fibrotic effects of CS-induced TGF- $\beta$ activity are fully consistent with other rodent models systems punctuated by injury-associated airspace enlargement.

What is the evidence for TGF- $\beta$ dysregulation in human COPD/ emphysema? Compelling genetic data from multiple laboratories implicate disturbances in TGF- $\beta$ signaling in COPD pathogenesis. However, the nature of the disturbance, too high or too low, is a subject of controversy. In several studies, TGF-b1 polymorphisms associate not only with the diagnosis of COPD but also with disease severity (31-34). However, other studies have not validated such associations $(33,35)$. Recently, polymorphisms in a TGF- $\beta$ binding protein (LTBP) and a TGF- $\beta$ coreceptor (betaglycan) were found to associate with distinct COPD-related subphenotypes $(31,36)$. Although a connection between TGF- $\beta$ polymorphisms and serum levels was initially presumed based on a few publications, subsequent studies in larger and more heterogeneous populations have not consistently shown this association (37-40). Immunohistochemical studies of COPD lung specimens show evidence of enhanced TGF- $\beta$ signaling predominantly in the airway compartment (41-43). Gene expression studies from lung specimens of patients with COPD demonstrate enhanced activation of TGF- $\beta$ pathways that may well be stage and compartment dependent (44-46). Interestingly, selective animal models with defects in TGF- $\beta$ signaling have also shown developmental or late-onset airspace enlargement (47-49). These seemingly conflicting findings suggest that a critical level of TGF- $\beta$ signaling is required for airspace formation and maintenance and that disorders resulting in either marked excess or profound deficiency in TGF- $\beta$ signaling translate into abnormal airspace architecture. Furthermore, the activation of compensatory mechanisms that serve to enhance TGF- $\beta$ signaling might be operative in these models (50). Thus, dysregulated TGF- $\beta$ signaling provides a unifying explanation for the divergent manifestations of COPD with cellular proliferation with fibrosis in terminal airways and apoptotic cell death in the alveolar compartment. Our data establish for what we believe to be the first time that enhanced TGF- $\beta$ activity is not merely a signature of COPD but contributes to disease pathogenesis.

We demonstrate an intriguing and previously unreported airway epithelial phenotype that approximates the epithelial hyperplasia that can accompany a variety of airway insults, including CS 
A
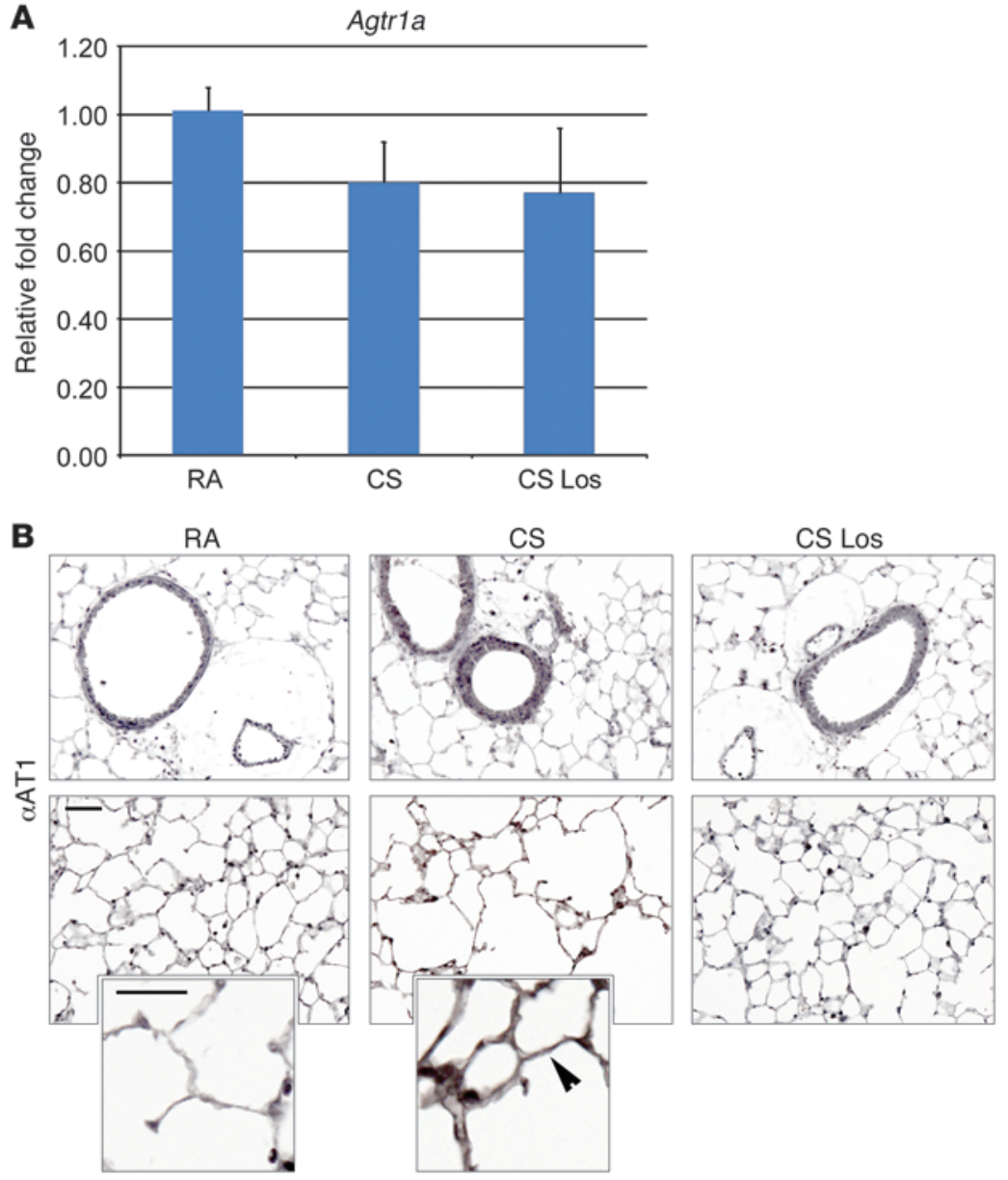

\section{Figure 7}

Angiotensin receptor expression in CS-exposed lungs. (A) Real-time PCR quantitation of AT1 (Agtr1a) expression in CS- and CS plus losartan-treated mice compared with that in RA controls. Receptor expression was normalized to Gapdh. Error bars represent SEM. $n=4-6$ mice per treatment group. (B) Representative lung sections stained for AT1 (black) in adult mice subjected to 2 months of RA, CS, or CS plus losartan. The arrowhead in the inset denotes enhanced staining for AT1 in the airspace wall of CS-exposed mice. Scale bar: $50 \mu \mathrm{m} ; 25 \mu \mathrm{m}$ (inset). $n=4-6$ mice per treatment or condition. Data are represented as mean \pm SEM.

MMP12 are protected against CS-induced emphysema (56). However, the role of TGF- $\beta$ signaling in metalloprotease expression and activation is highly contextual, with evidence of inductive effects on MMP9 and inhibitory effects on MMP12 (57-59). Further, reduced TGF- $\beta$ signaling seems to punctuate some models of aging-related airspace enlargement, possibly secondary to both a temporally defined impairment in maintenance elastogenesis and elevated MMP12 expression $(47,48)$. The scenario with CS appears distinct from this process. Since TGF- $\beta$ can induce MMP9 expression and MMP9 can activate TGF- $\beta$, our observed pattern of MMP9 activation is consistent with a TGF- $\beta$-mediated process (60-62). Whereas in the aging-associated airspace enlargement models, TGF- $\beta$ is thought to inhibit MMP12 expression in macrophages, our seemingly paradoxical result may reflect a direct effect of CS exposure on the proposed regulatory scheme and/or the enhanced macrophage abundance in the lungs of CS-exposed mice (47).

(reviewed in ref. 51). Airway wall thickening is a complex pathology in clinical COPD but seems to be a consequence of excessive TGF- $\beta$ activation $(42,52)$. Whether submucosal matrix deposition, airway epithelial thickening, or mucus hypersecretion is the critical pathologic lesion that accounts for clinical obstruction is debatable (13). Murine models typically display modest airway wall remodeling in response to chronic CS, an observation that is thought to be a consequence of the anatomic and cell compositional differences between the rodent and the primate airway (53). Nonetheless, clinical hyperexpansion with air trapping is a direct consequence of the airway lesion and is associated with accelerated lung function decline in patients with emphysema (54). Accordingly, in our model, the increased lung volumes likely follow from the airway mucosal thickening. A recent small clinical trial of angiotensin receptor blockade in patients with COPD similarly showed improvement in lung hyperexpansion with 4 months of treatment (55). Thus, the data generated in our preclinical model approximate effects observed in small studies of this agent in a comparable clinical population.

The current report suggests that enhanced TGF- $\beta$ is a therapeutic point of convergence for the inflammation, oxidative stress, cell death, and, importantly, metalloprotease activation associated with chronic CS exposure. Metalloprotease activation causing matrix turnover is a fundamental mechanism of COPD development and maintenance. Polymorphisms in MMP12 associate with reduced lung function in patients with COPD and children with asthma (31). Mice deficient in
Even though airspace maintenance in the setting of CS exposure must converge upon known cell injury and cell death prohas not been well dissected. Our studies provide some insight into these cascades. Using a combination of whole tissue and in situ analysis, we implicate reduced Akt signaling as potentially involved in the alveolar septal cell survival disturbance that culminates in enhanced cell death observed in the chronic CS model. Others have shown that Akt signaling is a critical mediator of airspace homeostasis in the setting of neonatal and adult hyperoxic injury $(63,64)$. Furthermore, several in vitro studies demonstrate that TGF- $\beta$ directly inhibits Akt-mediated lung epithelial cell survival $(65,66)$. We show that a similar mechanism may be operative with chronic CS-induced lung injury. The further dissection of Akt signaling in airspace repair is a fertile area of research for our laboratory.

We elected to forgo the use of the most common CS-induced emphysema model, the C57BL/6 mouse, in preference of the AKR/J strain. This choice was based on compelling data, suggesting that the $\mathrm{C} 57 \mathrm{BL} / 6$ model may be inferior to other strains, including AKR/J mice, with respect to the airspace lesion, inflammatory milieu, and effects on lung mechanics conferred by CS exposure $(11,67)$. Of particular concern with the C57BL/ 6 mouse is that the need for more than 6 months of CS exposures often results in the complicating phenotype of aging-associated airspace enlargement. cesses, the role of CS on prosurvival signaling in the airspace 
We report a murine model of CS-induced lung disease that manifests both airway wall thickening and airspace simplification after 2 months of smoke exposure. This model displays increased TGF- $\beta$ signaling and oxidative stress and inflammation in the airway and alveolar compartments. Altered cell survival signaling culminates in increased alveolar cell death. More importantly, we show that systemic antagonism of TGF- $\beta$ signaling with angiotensin receptor blockade normalizes histology and reduces oxidative stress, cell death, and inflammation. Pulmonary function studies show improved lung mechanics with losartan treatment. An exploratory transcriptional survey implicates the involvement of immunomodulatory and stress response pathways in the therapeutic effects of losartan. Our findings provide a preclinical platform for the development of other TGF- $\beta$-targeted interventions in translational approaches to COPD/emphysema.

\section{Methods}

Mice. Adult AKR/J mice were obtained from The Jackson Laboratory. These mice were housed in a facility accredited by the American Association of Laboratory Animal Care, and the animal studies were reviewed and approved by the institutional animal care and use committee of Johns Hopkins School of Medicine.

CS exposure. Six- to eight-week-old AKR/J male mice were divided into 3 groups. The control group was kept in a filtered air environment, and the experimental groups were subjected to CS or CS plus losartan in drinking water. CS exposure was carried out (2 hours per day, 5 days per week) by burning 2R4F reference cigarettes (University of Kentucky, Louisville, Kentucky, USA) using a smoking machine (Model TE-10; Teague Enterprises) for 6 to 7 weeks. The average concentration of total suspended particulates and carbon monoxide was $90 \mathrm{mg} / \mathrm{m}$ and $350 \mathrm{ppm}$, respectively, which was monitored on a routine basis.

Human studies. All human lung tissue from persons with COPD and atrisk controls were obtained, as anonymized samples, from the Lung Tissue Research Consortium (LTRC; http://www.nhlbi.nih.gov/resources/ltrc. htm), sponsored by the National, Heart Lung and Blood Institute. Based on spirometry and smoking history, the patients were designated as at-risk (>10 pack year history of smoking; normal spirometry) or as having moderate or severe COPD using Global Initiative for Chronic Obstructive Lung Disease (GOLD) criteria (moderate, GOLD, 2; forced expiratory volume at 1 second [FEV1], 50\%-80\% predicted; severe, GOLD, 3 and 4; FEV1, $<50 \%$ predicted) (68). All smokers were former smokers.

Cell treatment. MLE12 cells (ATCC) were treated with CSE for 72 hours after serum starvation overnight. CSE was generated per standard protocol by the D'Amico laboratory, Johns Hopkins School of Medicine (69). Cell lysates were harvested and subjected to immunoblotting for psmad2 (Cell Signaling Technology).

Treatment regimen. The AT1 selective antagonist losartan (Merck Co.) was diluted into drinking water at concentrations of $3 \mathrm{mg} / \mathrm{kg}$ (low dose) and $30 \mathrm{mg} / \mathrm{kg}$ (high dose). Panselective TGF- $\beta$-neutralizing antibody (R\&D Systems) was administered by intraperitoneal injection according to published protocol (70). Isotype-matched control antibody (R\&D Systems) was administered to control mice as described above.

Morphology and histology. Three to five mice of each genotype were studied at the noted ages. For histologic and morphometric analyses, mouse lungs were inflated at a pressure of $25 \mathrm{~cm} \mathrm{H}_{2} \mathrm{O}$ and fixed with 4\% PFA in low molecular weight agarose. The lungs were equilibrated in cold $4 \%$ PFA overnight, sectioned, and then embedded in paraffin wax. Sections were cut at $5 \mu \mathrm{m}$ and either stained with H\&E or processed for immunohistochemistry. For the human lung samples, 2-3 slides from each patient or control were used for analysis.
Morphometry and histochemistry. Mean linear intercept measurements were performed on H\&E-stained sections taken at intervals throughout both lungs. Slides were coded, captured by an observer, and masked for identity for the groups. Ten to fifteen images per slide were acquired at $\times 20$ magnification and transferred to a computer screen. Mean chord lengths and mean linear intercepts were assessed by automated morphometry with a macro-operation performed by Metamorph Imaging Software (Universal Imaging, Molecular Devices). Mean airway thickness was measured directly using microscope-captured images at $\times 40$ magnification. Hart's staining was performed per published protocol using either van Gieson or tartrazine counterstaining (71).

Immunoblotting. Whole lung lysates were extracted in M-Per buffer from Pierce. Protein concentrations were determined using the BioRad Protein Assay. Aliquots of 30-50 $\mu$ g protein were boiled and then loaded onto Tris-HCL gels and transferred electrophoretically to nitrocellulose membranes. Membranes were incubated with the primary antibody for 1 hour at room temperature. Detection was performed by the Pierce West Dura ECL Detection System. Primary antibodies and dilutions were as follows: $\beta$-actin (rabbit polyclonal, 1:1,000; Abcam), p38 (rabbit polyclonal, 1:1,000; Cell Signaling Technology), pp38 (goat polyclonal, 1:200; Cell Signaling Technology), ERK1 (rabbit polyclonal, 1:1,000; Cell Signaling Technology), pERK1 (rabbit polyclonal, 1:1,000; Cell Signaling Technology), JNK (rabbit polyclonal, 1:1,000; Cell Signaling Technology), and pJNK (rabbit polyclonal, 1:1,000; Cell Signaling Technology).

Immunohistochemistry. For details regarding protocol, please see the Supplemental Methods. Briefly, after incubation with the primary antibody overnight at $4{ }^{\circ} \mathrm{C}$, slides were washed with PBST, incubated with an appropriate biotinylated secondary antibody (Jackson ImmunoResearch Inc.), and developed by using $\mathrm{ABC}$ and $\mathrm{DAB}$ detection reagents (Vector Laboratories). Antibodies were used at the following concentrations: Ki67 (1:50; Santa Cruz Biotechnology Inc.), nitrotyrosine (Abcam), Mac3 (BD Biosciences), CD45R (Santa Cruz Biotechnology Inc.), psmad2 (Cell Signaling Technology), TUNEL (1:25; Abcam), JNK/pJNK (Cell Signaling Technology), Akt/pAkt (Cell Signaling Technology), LAP-TGF- $\beta 1$ (R\&D Systems), CTGF (Abcam), Angiotensin type 1 receptor (Santa Cruz Biotechnology Inc.), and active caspase-3 (Abcam).

Measurement of mouse lung mechanics. Mice were anesthetized with a ketamine $(90 \mathrm{mg} / \mathrm{kg}) / x y l a z i n e(18 \mathrm{mg} / \mathrm{kg})$ mixture. Once sedated, a tracheostomy was performed, and a cannula (18G) was inserted and connected to a constant flow ventilator as previously described (72).

Quasistatic PV curves were performed as previously reported (73). Details regarding protocol are in the Supplemental Methods.

Statistics. One-way ANOVA with Tukey's post-hoc test or Kruskal-Wallis nonparametric analysis with a Dunnett's post-hoc test were used to determine differences among groups. When 2 groups were compared, an unpaired, 2-tailed Student's $t$-test or a Wilcoxon rank-sum test was used. Values for all measurements were expressed as mean \pm SEM, and $P$ values for significance were less than 0.05 . The number of samples or animals in each group is indicated in the figure legends or text.

Study approval. For the LTRC specimens, all patients provided informed consent to the LTRC. We confirmed IRB-exempt status for these studies with the Johns Hopkins Office of Human Subjects Research (study no. NA_0051734).

\section{Acknowledgments}

We thank Robert Senior, Dean Sheppard, Ari Zaiman, and Landon King for helpful comments. We thank the Cytokine Core Laboratory at University of Maryland for the ELISA analyses. We thank the Biswal laboratory for supervising the CS expo- 
sure at the Core Facility in the Johns Hopkins School of Public Health. We thank the D'Amico laboratory for the provision of CSE. We thank Tracy Adair-Kirk for help with the Hart's stain assay. We thank Norman Barker for help with figure preparation. This work was supported by NIH grants R01HL085312 and R03HL095406-01 (to E.R. Neptune) and the NIH National Heart, Lung and Blood Institute Specialized Centers of Clinically Oriented Research Grant P50HL084945 (to E.R. Neptune, R. Wise, W. Mitzner, and S. Metzger). We would like to acknowledge the generous support of the Grace Anne Dorney fund for tobacco-related research.
Received for publication April 18, 2011, and accepted in revised form November 9, 2011.

Address correspondence to: Enid R. Neptune, Room 547, 1830 East Monument Street, Johns Hopkins University School of Medicine, Baltimore, Maryland 21205, USA. Phone: 410.955.4176; Fax: 410.955.0036; E-mail: eneptune@jhmi.edu.

Rubin Tuder's present address is: Program in Translational Lung Research, University of Colorado School of Medicine, Aurora, Colorado, USA.
1. Barnes PJ. New treatments for COPD. Nat Rev Drug Discov. 2002;1(6):437-446.

2. Habashi JP, et al. Losartan, an AT1 antagonist, prevents aortic aneurysm in a mouse model of Marfan syndrome. Science. 2006;312(5770):117-121.

3. Neptune ER, et al. Dysregulation of TGF-beta activation contributes to pathogenesis in Marfan syndrome. Nat Genet. 2003;33(3):407-411.

4. Lee CG, Kang HR, Homer RJ, Chupp G, Elias JA. Transgenic modeling of transforming growth factor-beta(1): role of apoptosis in fibrosis and alveolar remodeling. Proc Am Thorac Soc. 2006;3(5):418-423.

5. Sheppard D. Transforming growth factor beta: a central modulator of pulmonary and airway inflammation and fibrosis. Proc Am Thorac Soc. 2006;3(5):413-417.

6. Konigshoff M, Kneidinger N, Eickelberg O. TGFbeta signaling in COPD: deciphering genetic and cellular susceptibilities for future therapeutic regimen. Swiss Med Wkly. 2009;139(39-40):554-563.

7. Kagami S, Border WA, Miller DE, Noble NA. Angiotensin II stimulates extracellular matrix protein synthesis through induction of transforming growth factor-beta expression in rat glomerular mesangial cells. J Clin Invest. 1994;93(6):2431-2437.

8. Zhou Y, Poczatek MH, Berecek KH, Murphy-Ullrich JE. Thrombospondin 1 mediates angiotensin II induction of TGF-beta activation by cardiac and renal cells under both high and low glucose conditions. Biochem Biophys Res Commun. 2006; 339(2):633-641.

9. Li X, Rayford H, Uhal BD. Essential roles for angiotensin receptor AT1a in bleomycin-induced apoptosis and lung fibrosis in mice. Am J Pathol. 2003;163(6):2523-2530.

10. Marshall RP, et al. Angiotensin II and the fibroproliferative response to acute lung injury. Am J Physiol Lung Cell Mol Physiol. 2004;286(1):L156-L164.

11. Guerassimov A, et al. The development of emphysema in cigarette smoke-exposed mice is strain dependent. Am J Respir Crit Care Med. 2004;170(9):974-980.

12. Calvi CL, et al. Critical transition in tissue homeostasis accompanies murine lung senescence. PLoS One. 2011;6(6): 20712 .

13. Hogg JC, et al. The nature of small-airway obstruction in chronic obstructive pulmonary disease. $N$ Engl J Med. 2004;350(26):2645-2653.

14. Marwick JA, Kirkham P, Gilmour PS, Donaldson K, Mac NW, Rahman I. Cigarette smoke-induced oxidative stress and TGF-beta 1 increase $\mathrm{p} 21 \mathrm{waf} 1 / \mathrm{cip} 1$ expression in alveolar epithelial cells. Ann NY Acad Sci. 2002;973:278-283.

15. Stockley RA, Mannino D, Barnes PJ. Burden and pathogenesis of chronic obstructive pulmonary disease. Proc Am Thorac Soc. 2009;6(6):524-526.

16. Pavel J, et al. Increased angiotensin II AT1 receptor mRNA and binding in spleen and lung of AT2 receptor gene disrupted mice. Regul Pept. 2009;158(1-3):156-166.

17. Bullock GR, et al. Distribution of type-1 and type2 angiotensin receptors in the normal human lung and in lungs from patients with chronic obstructive pulmonary disease. Histochem Cell Biol.
2001;115(2):117-124

18. Conery AR, Cao Y, Thompson EA, Townsend CM Jr, Ko TC, Luo K. Akt interacts directly with Smad3 to regulate the sensitivity to TGF-beta induced apoptosis. Nat Cell Biol. 2004;6(4):366-372.

19. Undevia NS, Dorscheid DR, Marroquin BA, Gugliotta WL, Tse R, White SR. Smad and p38-MAPK signaling mediates apoptotic effects of transforming growth factor-beta 1 in human airway epithelial cells. Am J Physiol Lung Cell Mol Physiol. 2004;287(3):L515-L524.

20. Kang HR, Cho SJ, Lee CG, Homer RJ, Elias JA. Transforming growth factor (TGF)-beta1 stimulates pulmonary fibrosis and inflammation via a Bax-dependent, bid-activated pathway that involves matrix metalloproteinase-12. J Biol Chem. 2007;282(10):7723-7732.

21. Kaur S, Wang F, Venkatraman M, Arsura M. Xlinked inhibitor of apoptosis (XIAP) inhibits c-Jun $\mathrm{N}$-terminal kinase 1 (JNK1) activation by transforming growth factor beta 1 (TGF-beta1) through ubiquitin-mediated proteosomal degradation of the TGF-beta1-activated kinase 1 (TAK1). J Biol Chem. 2005;280(46):38599-38608

22. Chung KF, Adcock IM. Multifaceted mechanisms in COPD: inflammation, immunity, and tissue repair and destruction. Eur Respir J. 2008;31(6):1334-1356.

23. Sharafkhaneh A, Hanania NA, Kim V. Pathogenesis of emphysema: from the bench to the bedside. Proc Am Thorac Soc. 2008;5(4):475-477.

24. Morty RE, Konigshoff M, Eickelberg O. Transforming growth factor-beta signaling across ages: from distorted lung development to chronic obstructive pulmonary disease. Proc Am Thorac Soc. 2009;6(7):607-613.

25. Yamasaki $M$, et al. P21 regulates TGF-beta1induced pulmonary responses via a TNF-alphasignaling pathway. Am J Respir Cell Mol Biol. 2008; 38(3):346-353.

26 . Lee CG, et al. Early growth response gene 1-mediated apoptosis is essential for transforming growth factor beta1-induced pulmonary fibrosis. $J$ Exp Med. 2004;200(3):377-389.

27. Sime PJ, Sarnstrand B, Xing Z, Graham F, Fisher L, Gauldie J. Adenovirus-mediated gene transfer of the proteoglycan biglycan induces fibroblastic responses in the lung. Chest. 1997;111(6 suppl):137S.

28. Zhou L, Dey CR, Wert SE, Whitsett JA. Arrested lung morphogenesis in transgenic mice bearing an SP-C-TGF-beta 1 chimeric gene. Dev Biol. 1996;175(2):227-238

29. Lee CG, Cho S, Homer RJ, Elias JA. Genetic control of transforming growth factor-beta1-induced emphysema and fibrosis in the murine lung. Proc Am Thorac Soc. 2006;3(6):476-477.

30. Nakanishi H, Sugiura T, Streisand JB, Lonning SM, Roberts JD Jr. TGF-beta-neutralizing antibodies improve pulmonary alveologenesis and vasculogenesis in the injured newborn lung. Am J Physiol Lung Cell Mol Physiol. 2007;293(1):L151-L161.

31. Hunninghake GM, et al. MMP12, lung function, and COPD in high-risk populations. NEngl J Med. 2009;361(27):2599-2608

32. Cho MH, et al. Cluster analysis in severe emphyse- ma subjects using phenotype and genotype data: an exploratory investigation. Respir Res. 2010;11:30.

33. van Diemen CC, Postma DS, Vonk JM, Bruinenberg M, Nolte IM, Boezen HM. Decorin and TGF-beta1 polymorphisms and development of COPD in a general population. Respir Res. 2006;7:89.

34. Su ZG, Wen FQ, Feng YL, Xiao M, Wu XL. Transforming growth factor-beta1 gene polymorphisms associated with chronic obstructive pulmonary disease in Chinese population. Acta Pharmacol Sin. 2005;26(6):714-720.

35. Yoon HI, et al. Lack of association between COPD and transforming growth factor-beta1 (TGFB1) genetic polymorphisms in Koreans. Int J Tuberc Lung Dis. 2006;10(5):504-509.

36. Hersh CP, et al. Transforming growth factor-beta receptor-3 is associated with pulmonary emphysema. Am J Respir Cell Mol Biol. 2009;41(3):324-331.

37. Carrieri G, et al. The G/C915 polymorphism of transforming growth factor beta1 is associated with human longevity: a study in Italian centenarians. Aging Cell. 2004;3(6):443-448.

38. Grainger DJ, et al. Genetic control of the circulating concentration of transforming growth factor type beta1. Hum Mol Genet. 1999;8(1):93-97.

39. Rodriguez-Rodriguez E, et al. Serum levels and genetic variation of TGF-beta 1 are not associated with Alzheimer's disease. Acta Neurol Scand. 2007;116(6):409-412.

40. Suthanthiran M, et al. Transforming growth factorbeta 1 hyperexpression in African-American hypertensives: A novel mediator of hypertension and/or target organ damage. Proc Natl Acad Sci U S A. 2000;97(7):3479-3484.

41. Beghe B, et al. Transforming growth factor-beta type II receptor in pulmonary arteries of patients with very severe COPD. Eur Respir J. 2006; 28(3):556-562.

42. Takizawa $H$, et al. Increased expression of transforming growth factor-beta 1 in small airway epithelium from tobacco smokers and patients with chronic obstructive pulmonary disease (COPD). Am J Respir Crit Care Med. 2001;163(6):1476-1483.

43. Aubert JD, Dalal BI, Bai TR, Roberts CR, Hayashi S, Hogg JC. Transforming growth factor beta 1 gene expression in human airways. Thorax. 1994;49(3):225-232.

44. Ning W, et al. Comprehensive gene expression profiles reveal pathways related to the pathogenesis of chronic obstructive pulmonary disease. Proc Natl Acad Sci U S A. 2004;101(41):14895-14900.

45. Matsumoto M, et al. Exogenous heat shock protein-70 inhibits cigarette smoke-induced intimal thickening. Am J Physiol Regul Integr Comp Physiol. 2008;295(4):R1320-R1327.

46. Gosselink JV, et al. Differential expression of tissue repair genes in the pathogenesis of chronic obstructive pulmonary disease. Am J Respir Crit Care Med. 2010;181(12):1329-1335.

47. Morris DG, et al. Loss of integrin alpha(v) beta6-mediated TGF-beta activation causes Mmp12-dependent emphysema. Nature. 2003; 422(6928):169-173. 
48. Bonniaud P, et al. Smad3 null mice develop airspace enlargement and are resistant to TGFbeta-mediated pulmonary fibrosis. J Immunol. 2004;173(3):2099-2108.

49. Chen $\mathrm{H}$, et al. Abnormal mouse lung alveolarization caused by Smad 3 deficiency is a developmental antecedent of centrilobular emphysema. Am J Physiol Lung Cell Mol Physiol. 2005;288(4):L683-L691.

50. Farkas L, et al. Cigarette smoke exposure aggravates airspace enlargement and alveolar cell apoptosis in Smad3 knockout mice. Am J Physiol Lung Cell Mol Physiol. 2011;301(4):L391-L401.

51. Puchelle E, Zahm JM, Tournier JM, Coraux C. Airway epithelial repair, regeneration, and remodeling after injury in chronic obstructive pulmonary disease. Proc Am Thorac Soc. 2006;3(8):726-733.

52. Churg A, Wang RD, Wright JL. Cigarette smoke causes small airway remodeling by direct growth factor induction and release. Proc Am Thorac Soc. 2006;3(6):493.

53. Wright JL, Cosio M, Churg A. Animal models of chronic obstructive pulmonary disease. Am J Physiol Lung Cell Mol Pbysiol. 2008;295(1):L1-L15.

54. Sturton G, Persson C, Barnes PJ. Small airways: an important but neglected target in the treatment of obstructive airway diseases. Trends Pharmacol Sci. 2008;29(7):340-345.

55. Andreas S, et al. Angiotensin II blockers in obstructive pulmonary disease: a randomised controlled trial. Eur Respir J. 2006;27(5):972-979.

56. Hautamaki RD, Kobayashi DK, Senior RM, Shapiro SD. Requirement for macrophage elastase for cigarette smoke-induced emphysema in mice. Science. 1997;277(5334):2002-2004.

57. Feinberg MW, et al. Transforming growth factor-beta 1 inhibits cytokine-mediated induction of human metalloelastase in macrophages. $J$ Biol Chem. 2000;275(33):25766-25773.

58. Behzadian MA, Wang XL, Windsor LJ, Ghaly N, Caldwell RB. TGF-beta increases retinal endothelial cell permeability by increasing MMP-9: possible role of glial cells in endothelial barrier function. Invest Ophthalmol Vis Sci. 2001;42(3):853-859.

59. Li DQ, Lokeshwar BL, Solomon A, Monroy D, Ji $Z$, Pflugfelder SC. Regulation of MMP-9 production by human corneal epithelial cells. Exp Eye Res. 2001;73(4):449-459.

60. Safina A, Vandette E, Bakin AV. ALK5 promotes tumor angiogenesis by upregulating matrix metalloproteinase-9 in tumor cells. Oncogene. 2007; 26(17):2407-2422.

61. Tian YC, et al. Epidermal growth factor and transforming growth factor-beta1 enhance HK-2 cell migration through a synergistic increase of matrix metalloproteinase and sustained activation of ERK signaling pathway. Exp Cell Res. 2007;313(11):2367-2377.

62. Yu Q, Stamenkovic I. Cell surface-localized matrix metalloproteinase- 9 proteolytically activates TGFbeta and promotes tumor invasion and angiogenesis. Genes Dev. 2000;14(2):163-176.

63. el-Remessy AB, Bartoli M, Platt DH, Fulton D, Caldwell RB. Oxidative stress inactivates VEGF survival signaling in retinal endothelial cells via PI 3-kinase tyrosine nitration. J Cell Sci. 2005; 118(pt 1):243-252.

64. Alphonse RS, et al. Activation of akt protects alveoli from neonatal oxygen-induced lung injury. $A m J$ Respir Cell Mol Biol. 2011;44(2):146-154.

65. Ju EM, et al. Apoptosis of mink lung epithelial cells by co-treatment of low-dose staurosporine and transforming growth factor-beta 1 depends on the enhanced TGF-beta signaling and requires the decreased phosphorylation of PKB/Akt. Biochem Biophys Res Commun. 2005;328(4):1170-1181.

66. Solovyan VT, Keski-Oja J. Proteolytic activation of latent TGF-beta precedes caspase- 3 activation and enhances apoptotic death of lung epithelial cells. J Cell Physiol. 2006;207(2):445-453.

67. Lee KM, Renne RA, Harbo SJ, Clark ML, Johnson RE, Gideon KM. 3-week inhalation exposure to cigarette smoke and/or lipopolysaccharide in AKR/J mice. Inhal Toxicol. 2007;19(1):23-35.

68. Pauwels RA, Buist AS, Calverley PM, Jenkins CR, Hurd SS. Global strategy for the diagnosis, management, and prevention of chronic obstructive pulmonary disease. NHLBI/WHO Global Initiative for Chronic Obstructive Lung Disease (GOLD) Workshop summary. Am J Respir Crit Care Med. 2001;163(5):1256-1276.

69. Damico R, et al. p53 mediates cigarette smokeinduced apoptosis of pulmonary endothelial cells: inhibitory effects of macrophage migration inhibitor factor. Am J Respir Cell Mol Biol. 2011; 44(3):323-332.

70. Cohn RD, et al. Angiotensin II type 1 receptor blockade attenuates TGF-beta-induced failure of muscle regeneration in multiple myopathic states. Nat Med. 2007;13(2):204-210.

71. Pierce RA, Albertine KH, Starcher BC, Bohnsack JF, Carlton DP, Bland RD. Chronic lung injury in preterm lambs: disordered pulmonary elastin deposition. Am J Physiol. 1997;272(3 Pt 1):L452-L460.

72. Ewart S, Levitt R, Mitzner W. Respiratory system mechanics in mice measured by end-inflation occlusion. J Appl Physiol. 1995;79(2):560-566.

73. Soutiere SE, Mitzner W. On defining total lung capacity in the mouse. J Appl Physiol. 2004; 96(5):1658-1664 